\title{
Model Knowledge Management di Perpustakaan Universitas Padjadjaran
}

\author{
Eko Retno Wulandari ${ }^{1^{*}}$; Risa Nurisani ${ }^{1}$ \\ ${ }^{1}$ Universitas Padjadjaran
}

"Korespondensi: eko@unpad.ac.id

\begin{abstract}
Knowledge Management has an increasingly important role in organizations in various industries. Through Knowledge Management, organizations strive to acquire or create knowledge that is potential, useful and make it available to members of the organization so that it can be used at the right time and place to influence organizational performance positively. Padjadjaran University Library has not optimally managed the existing knowledge. Knowledge management in Padjadjaran University's library still limited to explicit knowledge, for example, textbooks, journals, e-books, e-journals, theses, thesis, and dissertations. However, there is still a lot of explicit and tacit knowledge that can be managed to bring benefits to the academic community and institution. The purpose of this study is to analyze and form a proposed model of Knowledge Management in the library of Padjadjaran University. This study was conducted using SWOT analysis to then obtain the KM model in the Padjadjaran University library. The results obtained by the proposed model of the process of Knowledge Management in the Padjadjaran University Library are knowledge creation, knowledge acquisition, knowledge storage, knowledge sharing, and application knowledge.
\end{abstract}

Keywords: knowledge management; knowledge management model; padjadjaran university library

\begin{abstract}
Abstrak
Knowledge Management mempunyai peran yang semakin penting dalam organisasi di berbagai industri. Melalui Knowledge Management, organisasi berusaha untuk memperoleh atau menciptakan pengetahuan yang berpotensi, bermanfaat dan membuatnya tersedia bagi anggota organisasi sehingga dapat digunakan pada waktu dan tempat yang tepat untuk secara positif mempengaruhi kinerja organisasi. Perpustakaan Universitas Padjadjaran belum mengelola pengetahuan yang ada secara maksimal. Pengelolaan pengetahuan di perpustakaan Universitas Padjadjaran masih terbatas pada pengetahuan eksplisit contohnya teksbook, jurnal, ebook, e-journal, skripsi, tesis, dan disertasi, padahal masih banyak pengetahuan eksplisit dan tacit yang dapat dikelola sehingga membawa manfaat bagi civitas akademika dan institusi. Tujuan penelitian ini adalah adanya model usulan Knowledge Management di perpustakaan Universitas Padjadjaran. Penelitian dilakukan dengan menggunakan analisis SWOT untuk kemudian diperoleh model KM di Perpustakaan Universitas Padjadjaran. Hasil penelitian diperoleh model usulan proses Knowledge Management di Perpustakaan Universitas Padjadjaran yaitu knowledge creation (penciptaan pengetahuan), knowledge acquisition (akuisisi pengetahuan), knowledge storage (penyimpanan pengetahuan) knowledge sharing (berbagi pengetahuan), dan knowledge application (aplikasi pengetahuan).
\end{abstract}

Kata Kunci: knowledge management; model knowledge management; perpustakaan universitas padjadjaran

\section{PENDAHULUAN}

Pengetahuan merupakan sumber daya tak berwujud, penting dan bernilai dalam sebuah organisasi (James, 2004), dan sumber pendukung untuk menciptakan keunggulan kompetitif yaitu kemampuan untuk memiliki kinerja yang lebih tinggi dibandingkan dengan organisasi lain (Aerts, Dooms, \& Haezendonck, 2017); (Nakauchi, Washburn, \& Klein, 2017). Organisasi saat ini mulai mengalihkan fokus mereka dari aset berwujud (tangible) seperti pabrik dan peralatan menjadi aset tidak berwujud (intangible) seperti pengetahuan, teknologi, dan inovasi (Obeidat, Hashem, Alansari, Tarhini, \& Al-Salti, 2016). Aset tangible tidak dianggap menjadi dasar keunggulan yang kompetitif lagi. Penggabungan sumber daya tangible dan intangible yang dikelola baik dengan menerapkan strategi akan menciptakan keunggulan kompetitif yang berkelanjutan (Mahdi, Nassar, \& Almsafir, 2018). Pengetahuan merupakan kombinasi dari pengalaman, nilai-nilai, informasi kontekstual, dan keahlian (Anantatmula \& Kanungo, 2010). 
Pengetahuan adalah aset dari suatu organisasi yang mempengaruhi penggunaan semua sumber daya dalam organisasi secara efisien. Pengetahuan adalah satu-satunya sumber daya yang tidak berkurang dengan berbagi. Dengan menggunakan dan membagikan pengetahuan ke setiap anggota organisasi, pengetahuan akan berkembang dan bertambah serta bermanfaat bagi kemajuan organisasi dan individu di dalamnya.

Manajemen Pengetahuan (Knowledge Management) mulai memainkan peran yang semakin penting dalam organisasi di berbagai industri. Melalui Knowledge Management, organisasi berusaha untuk memperoleh dan menciptakan pengetahuan yang bermanfaat dan membuatnya tersedia bagi anggota organisasi. Pengetahuan yang tersedia pada waktu dan tempat yang tepat dapat digunakan setiap anggota organisasi sehingga dapat bermanfaat dan digunakan secara efektif yang pada akhirnya secara positif mempengaruhi kinerja organisasi. Melalui manajemen pengetahuan, data dapat ditransformasikan menjadi informasi, dan menjadi pengetahuan, dan juga menjadi kebijaksanaan yang dapat membantu organisasi membuat keputusan yang lebih baik dan menambah pencapaian tujuan organisasi.

Penerapan manajemen pengetahuan dalam sebuah organisasi bermanfaat dalam meningkatkan layanan pada pelanggan, meningkatkan produktivitas, membantu organisasi dalam pengambilan keputusan yang lebih tepat, meningkatkan efisiensi dan efektivitas dalam proses dan cara kerja, serta dapat menghemat waktu dan biaya. Manajemen pengetahuan merupakan proses yang dimulai dengan penciptaan pengetahuan, proses penyimpanan, penyebaran dan pada akhirnya, bagaimana pengetahuan itu digunakan.

Perpustakaan perguruan tinggi adalah perpustakaan yang diselenggarakan oleh lembaga pendidikan tinggi yang layanannya diperuntukkan bagi civitas akademika perguruan tinggi yang bersangkutan. Perpustakaan perlu memberikan kontribusi nyata bagi perguruan tinggi yang menaunginya. Hal ini penting dilakukan untuk mendukung para penggunanya, untuk merasakan kepuasan dari pelayanan yang diberikan, yang kemudian berdampak pada terpenuhinya kebutuhan informasi pengguna yang berkaitan dengan peningkatan kemampuan ilmiah mereka. Keberhasilan perpustakaan perguruan tinggi salah satunya diukur pada kemampuan perpustakaan untuk memanfaatkan informasi dan pengetahuan guna memenuhi kebutuhan civitas akademika. Salah satu sumber penciptaan dan penyimpanan pengetahuan di sebuah Perguruan Tinggi adalah perpustakaan. Perpustakaan merupakan jantungnya Perguruan Tinggi yang berfungsi menyalurkan sumber-sumber informasi yang dikelola dan dimiliki untuk dapat dimanfaatkan seluruh civitas akademika. Di era digital ini terjadi perubahan bagaimana masyarakat memperoleh informasi dan pengetahuan. Layanan yang disediakan di perpustakaan harus mengikuti perubahan ini, sehingga menerapkan manajemen pengetahuan (Knowledge Management) menjadi suatu keharusan. Knowledge Management di perpustakaan perguruan tinggi akan mendorong pengumpulan pengetahuan dan diseminasi pengetahuan, mempromosikan hasil karya ilmiah civitas akademika, dan melindungi kekayaan intelektual. Penerapan Knowledge Management di perpustakaan perguruan tinggi agar pengetahuan tacit dan ekplisit disimpan sehingga jika diperlukan kembali oleh individu maupun organisasi dapat dimanfaatkan. Knowledge Management sebagai wadah repositori institusi perpustakaan perguruan tinggi untuk mendukung pengajaran, pembelajaran dan penelitian.

Manajemen pengetahuan di perguruan tinggi suatu kebutuhan untuk menggali kekuatan intelektual yang tersedia agar dibagikan kepada civitas akademika. Pengetahuan diperoleh dari pengetahuan yang sudah ada ataupun pengalaman masa lalu sehingga menghasilkan pengetahuan baru. Manajemen pengetahuan di perpustakaan Perguruan Tinggi penting untuk meningkatkan layanan melalui penciptaan, pengorganisasian, penyimpanan pengetahuan, mendukung budaya berbagi pengetahuan dan penggunaan aset intelektual. Manajemen pengetahuan di perpustakaan perguruan tinggi sangat penting untuk promosi inovasi, komunikasi dan meningkatkan kualitas 
layanan. Peran dan manfaat dari manajemen pengetahuan tidak hanya untuk kinerja perpustakaan, tetapi juga untuk meningkatkan produktivitas dan kinerja organisasi.

Meskipun demikian, ada kurangnya pemahaman implementasi dan kurangnya kejelasan tentang isu-isu manajemen pengetahuan (KM) dalam perpustakaan Perguruan Tinggi. Hanya 34\% dari perpustakaan universitas di India yang menerapkan manajemen pengetahuan di perpustakaan mereka (Rao, 2016). Sebuah studi tentang manajemen pengetahuan di perpustakaan akademik Rumania diperoleh hasil bahwa adanya kesadaran yang mendalam akan pentingnya penerapan manajemen pengetahuan di perpustakaan, namun pelaksanaannya belum efektif (Madge, 2017).

Hal ini juga terjadi di perpustakaan Universitas Padjadjaran. Pengelolaan pengetahuan di perpustakaan Universitas Padjadjaran masih terbatas pada pengetahuan eksplisit yaitu teksbook, jurnal, ebook, e-journal, skripsi, tesis, dan desertasi, padahal masih banyak pengetahuan eksplisit dan tacit yang dapat dikelola sehingga membawa manfaat bagi civitas akademika dan institusi. Proses manajemen pengetahuan memungkinkan perpustakaan Perguruan Tinggi untuk secara efektif berperan dalam pembelajaran, pengajaran, penelitian, dan peningkatan kinerja baik individu maupun institusi. Mengingat betapa pentingnya Knowledge Management dalam sebuah organisasi terutama bagi perguruan tinggi, maka fokus penelitian ini adalah membuat usulan model manajemen pengetahuan yang dapat diterapkan di Perpustakaan Universitas Padjadjaran. Tujuan penelitian ini adalah adanya model usulan Knowledge Management di perpustakaan Universitas Padjadjaran.

\section{METODE PENELITIAN}

Bogdan dan Taylor dalam (Moleong, 2000) mendefinisikan metode kualitatif sebagai prosedur penelitian yang menghasilkan data deskriptif berupa kata-kata tertulis atau lisan yang dapat diamati. Menurut mereka, pendekatan ini diarahkan pada latar belakang individu tersebut secara holistik. Jadi dalam hal ini tidak boleh mengisolasikan individu atau organisasi ke dalam variabel atau hipotesis tetapi perlu memandangnya sebagai bagian dari suatu hipotesis.

Penelitian ini menggunakan pendekatan kualitatif dengan jenis penelitian studi kasus. Studi kasus merupakan metode yang memberikan penjelasan secara mendalam dan komprehensif mengenai suatu aspek, baik organisasi, kelompok, program, situasi sosial, atau individu. Studi kasus berusaha meneliti sebanyak mungkin data mengenai subjek yang ingin diteliti (Yin, 2012).

Pada penelitian ini, peneliti menggunakan studi kasus deskriptif, memiliki tujuan untuk memberi gambaran mendalam mengenai studi kasus yang didalamnya memiliki pemaparan konsep-konsep penelitian, melalui pengumpulan data yang detail dan mendalam yang melibatkan beragam sumber informasi atau sumber informasi majemuk (wawancara, pengamatan, atau studi dokumen), dan melaporkan kasus dalam bentuk deskripsi. Pengumpulan data pada penelitian kualitatif ini dilakukan melalui observasi, dan wawancara. Observasi dilakukan dengan melakukan pengamatan pada situs yang dimiliki oleh perpustakaan Universitas Padjadjaran yaitu website Kandaga dan ULIMS. Website Kandaga adalah situs yang berisi repositori institusi Universitas Padjadjaran sedangkan ULIMS adalah sebuah sistem temu kembali informasi atau katalog online yang disediakan perpustakaan Universitas Padjadjaran. Dalam kedua situs tersebut belum ditemukan adanya sumber-sumber informasi yang berasal dari pengetahuan tacit, dan tidak semua hasil pengetahuan yang berasal pelatihan, workshop, seminar, dan sosialisasi disimpan didalamnya, padahal sumber-sumber pengetahuan dan informasi tersebut penting dalam Knowledge Management. Observasi juga dilakukan dengan kunjungan ke perpustakaan fakultas, dan perpustakaan pusat, hasilnya diperoleh bahwa tidak semua hasil workshop, seminar, dan pelatihan disimpan dan dikelola perpustakaan. Informan dalam penelitian ini adalah Pelaksana Harian Direktur Sumber Daya Akademik dan Perpustakaan, Koordinator Bidang Perpustakaan Pusat Universitas Padjadjaran, Koordinator Sub Bidang Scholarly Communication dan Repository 
Institusi, Koordinator Sub Bidang Pengembangan Perpustakaan. Informan yang diwawancarai sejumlah 4 orang yang merupakan jajaran pimpinan pengambil keputusan dan terjun langsung dalam pengembangan serta kemajuan Perpustakaan Universitas Padjadjaran. Waktu dan tempat penelitian dilakukan dari bulan April - Juni 2019 di Perpustakaan Universitas Padjadjaran.

\section{HASIL DAN PEMBAHASAN Pengetahuan}

Pengetahuan adalah kombinasi dari informasi, pengalaman dan wawasan (Empson, 1999 dalam Alhazmi, 2010), ditambah dengan potensi keterampilan, kompetensi, cita-cita, intuisi, komitmen, dan motivasi yang dapat menguntungkan individu atau organisasi (Bello, 2018). Pengetahuan berasal dari data yang diolah sebagai informasi ketika ditempatkan dalam konteks yang spesifik untuk berkontribusi dalam mengambil keputusan atau tindakan. Menurut Davenport, Thomas, \& Prusak (1998) mendefinisikan pengetahuan sebagai perpaduan campuran dari berbagai pengalaman, nilai-nilai, dan informasi kontekstual. Dalam sebuah organisasi, pengetahuan tidak hanya dalam dokumen atau repositori tetapi juga dalam rutinitas organisasi, proses, praktik, dan norma. Pengetahuan ada dua jenis yaitu tacit knowledge dan explisit knowledge.

Pengetahuan eksplisit dapat dikumpulkan dalam dokumen, sementara pengetahuan tacit berasal dari pemahaman dan pengalaman individu yang sulit didefinisikan (Davenport, Jarvenpaa, \& Beers, 1996; De Panjang \& Fahey, 2000; Grant, 1996; Nonaka, 1994; Sunassee \& Sewry, 2002; Varun \& Thomas, 2000 dalam Alhazmi, 2010). Pengetahuan eksplisit adalah pengetahuan sistematis, formal dan didokumentasikan, yang memungkinkan untuk didistribusikan, dibagikan dan dikomunikasikan secara jelas. Pengetahuan eksplisit dinyatakan dan dicatat sebagai kata-kata, kode, nomor matematika, dan prosedur ilmiah. Hal ini dapat ditemukan di internet, dalam bukubuku, dokumen, email dan sumber daya lainnya, baik lisan dan visual (Polanyi, 1997 dalam Alhazmi, 2010).

Di sisi lain, pengetahuan tacit tidak mudah diungkapkan, ditangkap, direkam, diformalkan dan diartikulasikan, bersifat pribadi, disimpan dalam pikiran individu, dan dikembangkan melalui interaksi sosial. Tantangan bagi organisasi adalah bagaimana dapat mengidentifikasi unsur-unsur pengetahuan tacit sehingga dapat diambil dan dibuat eksplisit. Menurut (Yusup, 2012) pengetahuan tacit dan ekplicit tidak dapat dipisahkan satu sama lain, mereka saling melengkapi, berinteraksi dalam lingkungan hubungan antar manusia, dan disebut proses konversi pengetahuan.

\section{Knowledge Management}

Menurut Galagan proses manajemen pengetahuan mencakup pengumpulan pengetahuan baru; mengakses pengetahuan dari sumber eksternal; penyimpanan pengetahuan dalam dokumen, database, dan perangkat lunak; penggunaan pengetahuan, dalam proses, produk atau layanan; mentransfer pengetahuan yang ada di sekitar organisasi; menggunakan pengetahuan yang dapat diakses dalam pengambilan keputusan; memfasilitasi pertumbuhan pengetahuan melalui budaya dan dorongan berbagi; dan mengevaluasi manajemen pengetahuan (Galagan, 1997 dalam Sirorei \& Fombad, 2019). Seleim dan Khalil mengklasifikasikan proses manajemen pengetahuan yang meliputi: penciptaan pengetahuan, transfer pengetahuan, pengorganisasian pengetahuan dan aplikasi pengetahuan (Seleim dan Khalil, 2007 dalam Sirorei \& Fombad, 2019).

Menurut (Ceptureanu, Ceptureanu, Olaru, \& Popescu, 2018), (Gonzalez \& Martins, 2017) menyatakan proses manajemen pengetahuan adalah penciptaan pengetahuan, penyimpanan pengetahuan, berbagi pengetahuan dan aplikasi pengetahuan. IFLA memberikan definisi kerja manajemen pengetahuan dengan menyebutnya sebagai proses menciptakan (menghasilkan atau menangkap), menyimpan (melestarikan dan mengatur), berbagi (berkolaborasi dan 
berkomunikasi), menerapkan dan menggunakan kembali (mentransformasikan) pengetahuan organisasi untuk mencapai tujuan dan sasarannya (IFLA, 2015).

Manajemen pengetahuan dapat diartikan sebagai sebuah kegiatan untuk mengelola suatu pengetahuan atau kemampuan seseorang maupun kelompok atau organisasi (Yusup, 2012). Knowledge Management dapat dijelaskan sebagai langkah-langkah sistematik untuk mengelola pengetahuan dalam organisasi untuk menciptakan nilai dan meningkatkan keunggulan kompetitif (Tjakraatmadja, J.H., Rachman \& Kristinawati, 2015).

Davenport et al., menyatakan terdapat empat tujuan dari knowledge management yaitu: (1) membuat knowledge repository, tujuan ini dicapai dengan mengambil tacit knowledge yang tersimpan di dalam dokumen tersebut dan kemudian menyimpannya dalam repositori sehingga dokumen tersebut dapat dengan mudah diakses. Aktivitas ini bertujuan untuk menangkap pengetahuan milik individu. (2) Meningkatkan akses knowledge, tujuan ini dicapai dengan menyediakan atau memfasilitasi perpindahan knowledge antar individu sehingga tercipta proses knowledge sharing. (3) Memperbesar knowledge environment, tujuan ini dicapai dengan menyediakan lingkungan yang dapat mengefektifkan penciptaan, berbagi, dan penggunaan pengetahuan. Penyediaan lingkungan tersebut erat kaitannya dengan membangun awareness dan budaya organisasi terhadap knowledge. (4) Mengelola knowledge sebagai aset, tujuan ini dicapai dengan memasukkan aset kekayaan intelektual kedalam laporan perusahaan (Davenport et al., 1998).

Menurut Amrit Tiwana manajemen pengetahuan perusahaan dilaksanakan dalam rangka menciptakan nilai bisnis (business value) dan menghasilkan keunggulan kompetitif yang berkesinambungan (sustainable competitive advantage). Knowledge Management mengoptimalkan proses penciptaan, pengkomunikasian, dan pengaplikasian semua pengetahuan yang dibutuhkan dalam rangka pencapaian tujuan bisnis (Lumbantobing, 2011).

\section{Komponen Knowledge Management}

Knowledge Managemen terdapat tiga komponen yaitu people, process, dan technology. Hubungan tiap elemen bersifat resiprokal dengan kedua elemen lainnya. Sebagai contoh, people merancang dan mengoperasikan proses sedangkan process akan mendefinisikan peran people dalam melaksanakan proses dan knowledge yang dibutuhkan dalam menjalankan proses tersebut.

Pelaksanaan Knowledge Management melibatkan tiga komponen yaitu (1) Manusia. Pada dasarnya pengetahuan berada di dalam pikiran manusia berupa pengetahuan tacit. Manusia memegang salah satu peranan penting dalam terwujudnya manajemen pengetahuan sebagai sumber dari pengetahuan. Disamping sebagai sumber pengetahuan, manusia juga merupakan pelaku dari proses-proses yang ada di manajemen pengetahuan. Ketersediaan manusia yang kompeten mendukung dalam berhasilnya penerapan KM. Kompetensi manusia yang ada didalamnya perlu dikembangkan dan memastikan masing-masing anggota organisasi mengetahui peran dan tanggung jawab dalam mengelola pengetahuan; (2) Proses. Proses yang jelas akan mempermudah penciptaan dan tranfer pengetahuan; (3) Teknologi. Perkembangan teknologi informasi (TI) yang pesat sekarang ini menjadikannya salah satu enabler dari implementasi manajemen pengetahuan. Perkembangan TI menyebabkan semakin banyak proses yang diotomasi. Perkembangan teknologi internet berbasis aplikasi di dalamnya membuat teknologi ini menjadi basis utama dalam pengembangan $K M$ tool. Teknologi berkontribusi dalam mendorong terlaksananya proses manajemen pengetahuan di dalam suatu organisasi, dimana teknologi dapat menunjang implementasi manajemen pengetahuan berjalan dengan lebih cepat melalui pendistribusian pengetahuan yang lebih baik. Tujuan utamanya adalah untuk membantu pendistribusian pengetahuan melalui internet/intranet yang memungkinkan pengetahuan yang dimiliki perusahaan dan karyawan tersebar, dan menjadi milik kolektif perusahaan atau 
organisasi. Teknologi akan membantu kolaborasi dan komunikasi proses KM untuk menyimpan, menangkap, dan mempermudah penggunaan pengetahuan.

\section{Knowledge Management di Perpustakaan Universitas Padjadjaran}

Perguruan Tinggi mempunyai sumber pengetahuan yang berlimpah dimana pengetahuan diciptakan, dan digunakan terus menerus. Perguruan tinggi perlu mengatur dan mengelola pengetahuan yang dimilikinya. Pengelolaan Knowledge Management (KM) secara sistematis akan menjadi alat yang ampuh untuk meningkatkan produktivitas civitas akademika. Jika KM dioperasikan di suatu perguruan tinggi sebagai kegiatan yang berkelanjutan maka pengetahuan dapat ditangkap, dicatat, dihasilkan serta disimpan dengan baik untuk penggunaan di masa mendatang. Pengetahuan yang tersimpan dapat digunakan untuk pengambilan keputusan, dan pembuatan strategi untuk memajukan perguruan tinggi. Dengan adanya KM, pengetahuan tidak hanya dimanfaatkan oleh individu tetapi pengetahuan dapat disebarkan dan diaplikasikan oleh seluruh civitas akademika.

Sejumlah besar pengetahuan yang tersimpan di perpustakaan secara keseluruhan membutuhkan manajemen pengetahuan, karena saat ini penting bagi institusi pendidikan menyediakan informasi yang berkualitas, pengambilan keputusan yang efektif, peningkatan pada kinerja serta meningkatkan peran perpustakaan sebagai sumber informasi di sebuah perguruan tinggi. Universitas Padjadjaran sudah mengelola pengetahuan yang dimilikinya salah satunya melalui perpustakan. Perpustakaan perguruan tinggi mempunyai visi misi mendukung pengajaran, penelitian dan pengabdian masyarakat dengan mengumpulkan dan menyebarkan sumber informasi yang dimiliki. Pengelolaan sumber informasi di perpustakaan Universitas Padjadjaran masih berprioritas pada pengetahuan ekplisit. Perpustakaan Universitas Padjadjaran lebih banyak mengelola pengetahuan eksplisit contohnya teksbook, jurnal cetak, e-book, e-journal, skripsi, tesis, dan disertasi. Namun demikian banyak pengetahuan eksplisit yang belum dikelola perpustakaan Universitas Padjadjaran contohnya hasil laporan penelitian dosen. Sedangkan pengetahuan tacit belum dikelola dengan baik oleh perpustakaan. Pengetahuan tacit yang masih tersembunyi, masih dalam bentuk pemikiran dan ide jika dikelola dengan baik akan sangat bermanfaat bagi individu maupun institusi. Pengetahuan menjadi sumber daya strategis, yang ketika dikelola dengan baik akan mempercepat inovasi, berperan dalam pengambilan keputusan, dan peningkatan kinerja organisasi. Pengelolaan pengetahuan dapat dilakukan dengan manajemen pengetahuan. KM dapat meningkatkan pembelajaran organisasi untuk mencapai tujuan. Banyaknya sumber informasi, dan keilmuan di Universitas Padjadjaran, harus dikelola dengan baik agar pengetahuan yang sudah ada tidak mudah hilang. Kegiatan berbagi pengetahuan yang sudah dilakukan baru sebatas kegiatan informal dan seringkali tidak terdokumentasikan dengan baik. Pengelolaan pengetahuan tersebut diperlukan sebuah sistem yang disebut sistem manajemen pengetahuan.

Selain adanya sistem manajemen pengetahuan di perpustakaan perguruan tinggi, sumber daya manusia merupakan faktor utama dalam proses manajemen pengetahuan. Sebaik apapun sistem yang ada jika organisasi tidak mempunyai sumber daya manusia yang mempunyai pengetahuan dalam mengelola manajemen pengetahuan maka sistem yang bagus tidak ada gunanya. Pustakawan diharapkan untuk menyadari pentingnya aset pengetahuan di sebuah organisasi, bagaimana mengelola pengetahuan tersebut serta memanfaatkan aset tersebut untuk mendapatkan kepuasan maksimum bagi penggunanya.

Sebelum menentukan model Knowledge Management penulis menggunakan analisis SWOT untuk mengetahui kekuatan, kelemahan, peluang dan tantangan di perpustakaan Universitas Padjadjaran. Analisis SWOT merupakan sebuah metode perencanaan strategis yang digunakan untuk mengevaluasi kekuatan, kelemahan, peluang, dan ancaman dalam suatu proyek atau suatu 
spekulasi bisnis. Menurut Rangkuti, analisis SWOT adalah identitas berbagai faktor secara sistematis untuk merumuskan strategi pelayanan. Analisis ini berdasarkan logika yang dapat memaksimalkan peluang namun secara bersamaan dapat meminimalkan kekurangan dan ancaman (Rangkuti, 2015).

Hasil analisis SWOT di perpustakaan Universitas Padjadjaran berdasarkan kajian lingkungan internal dan eksternal dapat dilihat pada table 1 berikut:

Tabel 1

Analisis SWOT Universitas Padjadjaran

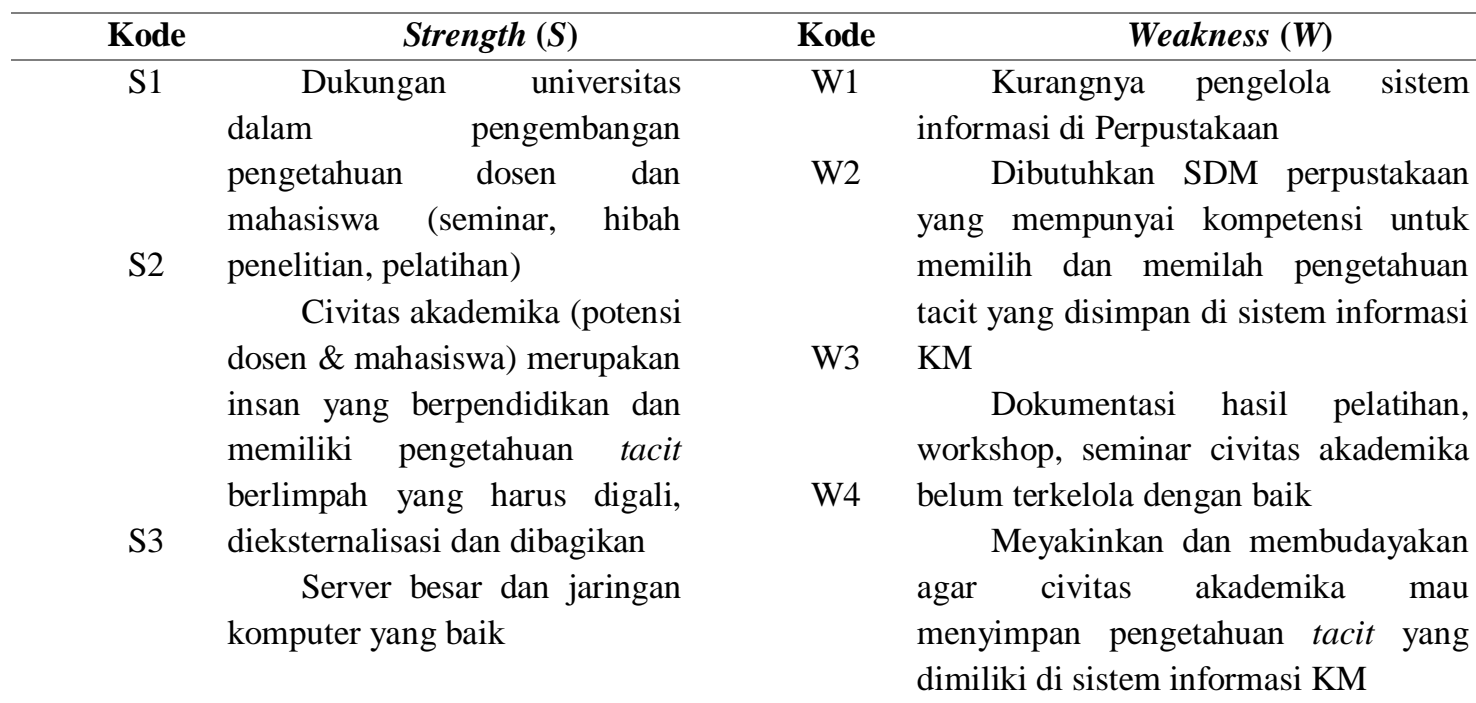

\begin{tabular}{|c|c|c|c|}
\hline Kode & Opportunity $(O)$ & Kode & Threat $(T)$ \\
\hline $\mathrm{O} 1$ & Era digital (internet, sosial & $\mathrm{T} 1$ & Adanya pengetahuan tacit yang \\
\hline $\mathrm{O} 2$ & media) & & hilang dan tidak tersimpan di sistem \\
\hline & Kerjasama & $\mathrm{T} 2$ & informasi KM \\
\hline & yang sudah menerapkan KM & & $\begin{array}{l}\text { Pengetahuan tacit civitas } \\
\text { akademika sulit dikomunikasikan atau } \\
\text { diubah menjadi eksplisit }\end{array}$ \\
\hline
\end{tabular}

Dari hasil analisis SWOT menghasilkan empat (4) kemungkinan prioritas usulan strategi alternatif, yaitu:

(1) Strategi SO (Strength and Opportunities), yaitu strategi yang mengoptimalkan kekuatan untuk memanfaatkan peluang, yaitu: membuat repositori untuk penyimpanan pengetahuan tacit dan eksplisit civitas akademika. Adanya kebijakan pimpinan untuk membuat repositori KM di perpustakaan Universitas Padjadjaran. Peran pemimpin dan kebijakan organisasi akan berpengaruh pada sisi dukungan dan komitmen dalam mengimplementasikan manajemen pengetahuan tersebut di dalam organisasi. Seluruh civitas akademika mempunyai potensi pengetahuan yang berlimpah, dengan diterapkannya Knowledge Management perpustakaan Universitas Padjadjaran menangkap dan mengelola pengetahuan tacit dan ekplisit.

(2) Strategi WO (Weaknesses and Opportunities), yaitu strategi yang meminimalkan kelemahan untuk memanfaatkan peluang, yaitu: meningkatkan kompetensi SDM Perpustakaan Universitas Padjadjaran dan kesiapan menggunakan sistem informasi KM dan meningkatkan kompetensi untuk memilih dan memilah pengetahuan tacit yang telah tersimpan di sistem informasi KM. Pustakawan dapat melakukan upaya yang lebih baik dengan menyediakan pengetahuan sesuai kebutuhan pengguna dengan dukungan teknologi untuk menangkap 
pengetahuan tacit dan ekplisist yang dihasilkan civitas akademika. Penerapan Knowledge Management bukan hanya tanggung jawab pustakawan tetapi merupakan tanggung jawab bersama yaitu pimpinan, tenaga pendidik, dan mahasiswa.

(3) Strategi ST (Strength and Threats), yaitu strategi yang menggunakan kekuatan untuk mengatasi ancaman, yaitu: meningkatkan kesiapan sumber daya teknologi informasi, menerapkan kebijakan transfer dan penyimpanan pengetahuan tacit di dalam sistem informasi KM, serta membangun kesadaran budaya berbagi pengetahuan. Faktor penting dalam berbagi pengetahuan adalah kepercayaan (trust) dan komitmen organisasi. Berbagi pengetahuan akan dapat berjalan dengan maksimal jika kepercayaan diantara civitas akademika terbangun dengan baik karena pemilik pengetahuan lebih memilih untuk membagi pengetahuan yang dimilikinya dengan orang yang dapat dipercaya. Saling percaya (trust) merupakan pondasi budaya untuk berbagi pengetahuan. Civitas akademika harus percaya bahwa ide dan masukannya terhadap institusi bagaimanapun kualitasnya akan mendapat penghargaan bukan cemoohon atau celaan. Menurut Tobing, trust dihasilkan melalui interaksi dan pergaulan informal antar personil dan tidak dapat dibangun dengan seketika (Tobing, 2007).

(4) Strategi WT (Weaknesses and Threats), yaitu strategi yang meminimalkan kelemahan dan menghindari ancaman, yaitu: dokumentasi hasil penelitian dosen dikelola perpustakaan dengan menggunakan teknologi yaitu adanya repositori. Kebijakan institusi untuk mewajibkan hasil pelatihan, workshop, seminar yang diikuti tenaga pendidik dan mahasiswa disimpan dalam repositori. Hasil diskusi tenaga pendidik dan mahasiswa disimpan juga di repositori. Perpustakaan dapat berperan dengan menyediakan tempat untuk diskusi tenaga pendidik, mahasiswa atau tenaga pendidik dan mahasiswa. Merupakan tugas dan kewajiban perpustakaan untuk dapat menyediakan sumber informasi dalam mendukung Tri Dharma Perguruan Tinggi. Sumber informasi yang disediakan adalah koleksi yang mendukung pencapaian tujuan pembelajaran, dan penelitian civitas akademika. Setelah mengetahui strategi untuk implementasi Knowledge Management, Perpustakaan Universitas Padjadjaran menyiapkan langkah-langkah untuk proses KM sehingga didapatkan model KM yang sesuai dengan keadaan dan kondisi Perpustakaan Universitas Padjadjaran.

Dalam penelitian ini usulan Knowledge Management di Perpustakaan Universitas Padjadjaran, mempertimbangkan lima proses pengetahuan utama (Mertins, Heisig, \& Vorbeck, 2013); (Ranjbarfard, Aghdasi, López-Sáez, \& Emilio Navas López, 2014); (González \& Bello, 2002); (Sirorei \& Fombad, 2019) yaitu: knowledge creation (penciptaan pengetahuan), knowledge acquisition (akuisisi pengetahuan), knowledge storage (penyimpanan pengetahuan) knowledge sharing (berbagi pengetahuan), dan knowledge application (aplikasi pengetahuan).

\section{Knowledge creation (penciptaan pengetahuan)}

Penciptaan pengetahuan melibatkan, menghasilkan atau menemukan pengetahuan baru dengan berbagai cara antara lain melalui: penelitian dan pengembangan, inovasi atau pembelajaran, sementara yang lain menganggapnya sebagai pelengkap untuk memperoleh pengetahuan. Penemuan dan penciptaan pengetahuan adalah proses pengidentifikasian pengetahuan, terutama pengetahuan tacit (Ceptureanu et al., 2018). Hilangnya pengetahuan karena tenaga pendidik pensiun, mahasiswa lulus, ketika pembelajaran dan seminar, workshop yang tidak ditangkap, dan prosedur yang tidak efisien. Karena itu perguruan tinggi perlu menangkap dan mengakuisisi pengetahuan untuk mencegah hilangnya pengetahuan dan membangun memori institusi. Cara ini perguruan tinggi akan mendapat keunggulan kompetitif, meningkatkan kinerja institusi, dan untuk pengambilan keputusan yang efisien dan efektif. 
Penemuan dan penciptaan pengetahuan mencakup penemuan dan pengumpulan pengetahuan baru baik tacit maupun eksplisit. Penciptaaan pengetahuan melibatkan semua civitas akademik. Penemuan dan penciptaan pengetahuan diperoleh melalui komunikasi face to face dan komunikasi virtual. Pelatihan, workshop, dan seminar merupakan salah satu bentuk penciptaan pengetahuan. Tenaga pendidik dan mahasiswa mengikuti pelatihan, workshop, lokakarya dan seminar untuk meningkatkan dan memperoleh pengetahuan dan kemampuan baru.

Perpustakaan Universitas Padjadjaran membuat kebijakan tertulis yang akan membantu menetapkan SOP untuk civitas akademika agar mau berbagi pengetahuan. Semua pelatihan, lokakarya, workshop, dan seminar yang diikuti oleh civitas akademika wajib disimpan dalam repositori KM. Divisi pengembangan dan pengolahan menampung pengetahuan-pengetahuan tacit dan ekplisit yang dimiliki civitas akademika.

Penciptaan pengetahuan yang berasal dari obrolan di grup media sosial, dan diskusi virtual dilakukan Universitas Padjadjaran dengan membuat kebijakan, menghimbau, dan mensosialisasikan bahwa informasi dan pengetahuan dari diskusi virtual dan obrolan di grup media sosial disimpan di sistem informasi KM. Tim Direktorat Teknologi dan Sistem Informasi membuat dan menyediakan aplikasi sistem informasi $\mathrm{KM}$ agar civitas akademika dapat mengunggah pengetahuan hasil diskusi virtual.

\section{Knowledge acquisition (akuisisi pengetahuan)}

Setelah memperoleh pengetahuan, pengetahuan baru yang diperoleh dikodekan dan dicatat untuk memudahkan dalam penemuan kembali. Knowledge Acquisition atau akuisisi pengetahuan adalah proses pengumpulan pengetahuan tacit dan pengetahun eksplisit mulai dari individu dan mengintegrasikan tingkat organisasi serta identifikasi dan penyerapan informasi dan sumber pengetahuan eksternal meliputi penyerapan pengetahuan, pengorganisasian pengetahuan, transformasi pengetahuan, dan proses kreatif (Gonzalez \& Martins, 2017). Menurut Schwartz \& Brasethvi, akuisisi pengetahuan berkaitan dengan cara mengumpulkan pengetahuan dari anggota organisasi atau sumber lain dan menyimpan pengetahuan dalam memori institusi (Schwartz \& Brasethvi, 2000 dalam Aming'a, 2015). Sebuah proses akuisisi pengetahuan dalam suatu organisasi bertujuan memperoleh pengetahuan dari sumber-sumber internal dan eksternal. Pengetahuan ini kemudian dikembangkan untuk meningkatkan keunggulan kompetitif organisasi. Pengetahuan yang diperoleh baik pengetahuan tacit maupun eksplisit harus menambah nilai bagi organisasi.

Pengorganisasian pengetahuan berkaitan dengan kegiatan seperti deskripsi dokumen, pengindeksan, dan klasifikasi yang dilakukan di perpustakaan. Divisi bidang pengolahan mencatat, mengkode, dan mengklasifikasikan pengetahuan agar memudahkan dalam penemuan kembali informasi. Cara terbaik untuk menentukan pengorganisasian pengetahuan adalah sistem berdasarkan pendekatan yang berorientasi pada pengguna. Penentuan bagaimana sistem pengorganisasian pengetahuan yang dibuat agar mempermudah pengguna dalam penemuan kembali informasi, dan user-friendly (Hjørland, 2008). Pengorganisasian pengetahuan melibatkan kegiatan mengklasifikasikan, memetakan, mengindeks, dan mengkategorikan pengetahuan untuk navigasi, penyimpanan, dan pengambilan kembali pengetahuan (Botha A \& R, 2008). Pengorganisasian pengetahuan bertujuan agar pengetahuan dapat diidentifikasi, diambil, dipahami pengguna, dan mempermudah penemuan kembali pengetahuan dan informasi.

\section{Knowledge storage (penyimpanan pengetahuan)}

Organisasi harus mengembangkan repositori pengetahuan di mana mereka menyimpan pengetahuan mereka (Aming'a, 2015). Menurut Ceptureanu et al, penyimpanan pengetahuan melibatkan penyimpanan selektif dari pengetahuan yang ada, diperoleh, dan dibuat dalam 
berbagai repositori pengetahuan yang sesuai, hasil dari akumulasi aset pengetahuan dari waktu ke waktu (Ceptureanu et al., 2018). Teknologi diterapkan dalam mengembangkan sistem KM untuk menekankan pentingnya pengintegrasian informasi dan pengetahuan yang ada. Tahap penyimpanan pengetahuan mengacu pada proses pembentukan memori institusi, di mana pengetahuan secara resmi disimpan. Teknologi informasi (TI) sebagai alat utama dalam fase ini, menawarkan tiga aplikasi yaitu encoding dan berbagi pengetahuan, penciptaan pengetahuan direktori perusahaan, penciptaan jaringan pengetahuan (Gonzalez \& Martins, 2017).

Aset pengetahuan harus disimpan dengan cara terstruktur yang memungkinkan penggunaan dan berbagi secara efisien. Perpustakaan perguruan tinggi menggunakan teknologi dengan membuat repositori institusi KM. Saat ini repositori perpustakaan Universitas Padjadjaran terbatas pada pengetahuan eksplisit. Pustakawan harus mempunyai kemampuan untuk memilah pengetahuan yang akan diambil dan disimpan dalam repositori institusi. Pengetahuan yang disimpan dalam repositori institusi merupakan salah satu promosi perguruan tinggi dalam menunjang pembelajaran, pendidikan, dan penelitian.

Selanjutnya pengetahuan tacit yang terkumpul dan telah menjadi pengetahuan eksplisit dipilih dan diolah oleh divisi pengolahan. Divisi pengolahan bertugas untuk memilih, memilah dan memvalidasi pengetahuan yang masuk dalam sistem informasi KM. Disini divisi ini harus diisi oleh orang yang mempunyai pengetahuan luas dan berkompetensi, sehingga pengetahuan yang disebarkan nanti adalah pengetahuan yang bermanfaat untuk kemajuan institusi. Tim Direktorat Teknologi dan Sistem Informasi Universitas Padjadjaran sebagai divisi yang melayani layanan infrastruktur sistem informasi dan penyedia layanan perangkat lunak mengelola dan membuat sistem manajemen pengetahuan untuk menyimpan dan menyebarkan pengetahuan yang diperoleh dari Knowledge Management.

\section{Knowledge sharing (berbagi pengetahuan)}

Berbagi pengetahuan melibatkan distribusi pengetahuan yang ada dalam organisasi, baik di tingkat organisasi maupun individu (Ceptureanu et al., 2018). Berbagi pengetahuan mengacu pada proses berbagi informasi dari berbagai sumber dan akhirnya dapat mendorong penciptaan pengetahuan, pemahaman dan informasi baru. Berbagi pengetahuan jika dilakukan secara terus menerus dalam organisasi secara bertahap akan berdampak kepada perbaikan dan pengembangan organisasi.

Pengetahuan di perpustakaan dapat disebarluaskan melalui berbagai aset pengetahuan seperti sistem informasi perpustakaan, dan website perpustakaan. Pengetahuan yang sudah disimpan dalam repositori institusi disebarluaskan melalui sistem informasi perpustakaan, dimana civitas akademika dapat mengakses repositori institusi sesuai kebijakan dan aturan institusi. Selanjutnya berbagi pengetahuan digunakan kembali dalam pembelajaran, seminar, lokakarya dan penelitian hingga publikasi. Selain itu perpustakaan perlu melakukan promosi dalam membangun budaya berbagi pengetahuan dengan mengadakan pelatihan penelusuran informasi dan cara mengakses informasi di repositori institusi secara berkala.

\section{Knowledge application (penggunaan pengetahuan)}

Aplikasi pengetahuan melibatkan pengambilan dan penggunaan pengetahuan untuk mendukung keputusan, memulai tindakan, memecahkan masalah, serta secara keseluruhan menggunakan pengetahuan secara produktif (Ceptureanu et al., 2018). Menurut Zack, penggunaan pengetahuan dikaitkan dengan kemampuan individu dari suatu organisasi untuk menemukan, mengakses, dan menggunakan informasi dan pengetahuan yang disimpan dalam organisasi sistem memori formal dan informal. Penggunaan pengetahuan menekankan (1) bagaimana menggunakan pengetahuan; (2) membahas kemampuan dinamis organisasi untuk membangun kembali 
keterampilannya dalam proses pembelajaran; (3) proses pengambilan dan transformasi pengetahuan ini dalam organisasi (Zack, 1999 dalam Gonzalez \& Martins, 2017).

Pengetahuan yang disimpan di repositori institusi digunakan kembali oleh civitas akademika Universitas Padjadjaran untuk menyelesaikan masalah, mengambil keputusan dalam mendukung pembelajaran, penelitian, dan pengabdian bagi masyarakat. Dengan adanya kumpulan pengetahuan dan informasi baru yang diperoleh dari pengetahuan tacit dan ekplisit Perguruan Tinggi diharapkan mempunyai sumber daya manusia yang unggul, inovatif, dan berkinerja tinggi.

Penggunaan pengetahuan adalah kunci untuk integrasi bentuk pengetahuan tacit. Konversi pengetahuan eksplisit menjadi pengetahuan tacit diterapkan melalui berbagai metode pelatihan, seperti: simulasi, pembelajaran aktif, pengalaman dan sebagainya. Model knowledge management hasil paparan penulis di atas divisualisasikan dalam gambar 1 di bawah ini:

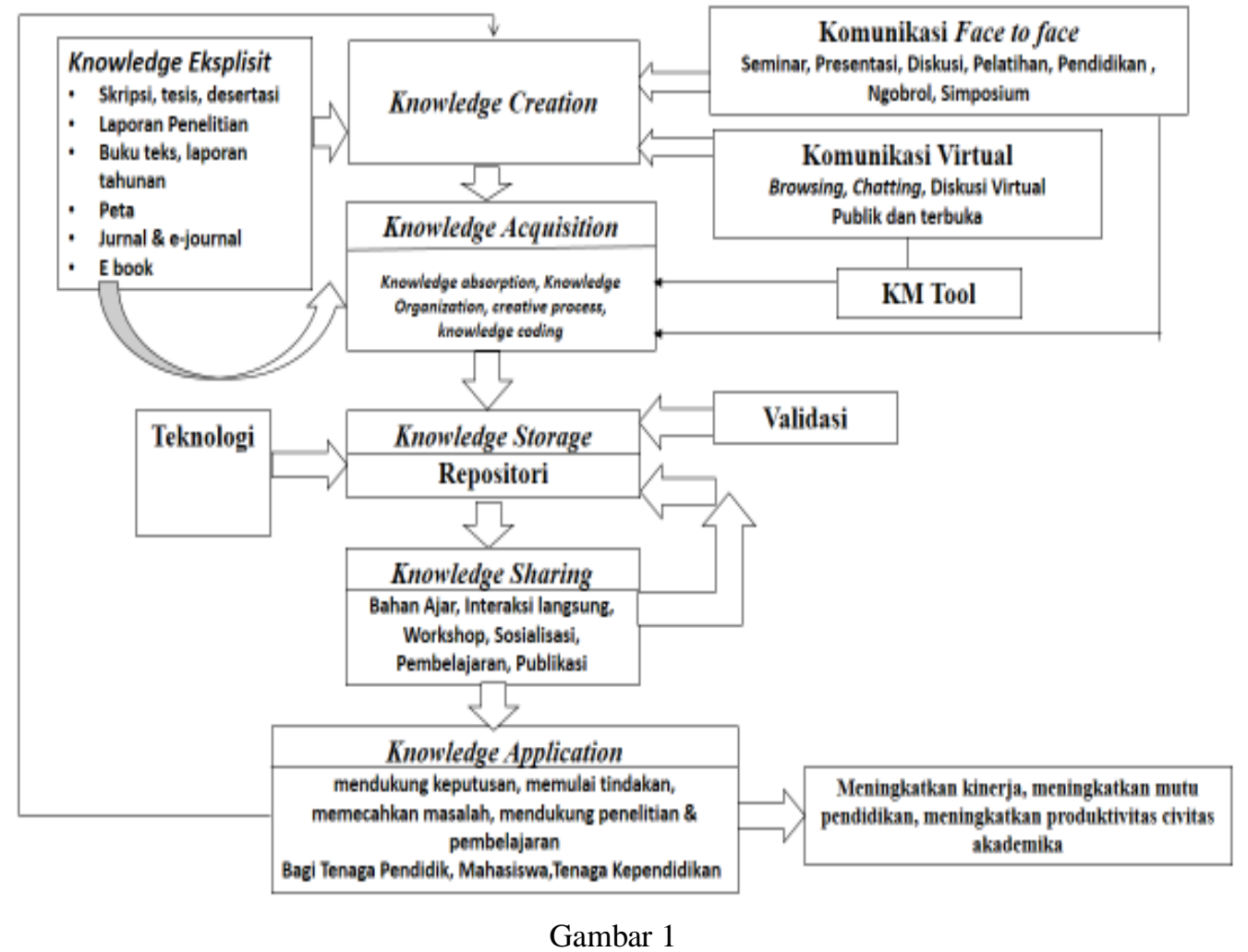

Model Usulan Knowledge Management di Perpustakaan Universitas Padjadjaran

\section{SIMPULAN}

Strategi usulan dalam implementasi Knowledge Management di Perpustakaan Universitas Padjadjaran yaitu adanya kebijakan pimpinan untuk membuat repositori KM dan mewajibkan civitas akademika menyimpan hasil seminar, pelatihan dan workshop di repositori, meningkatkan kesiapan teknologi informasi, meningkatkan kompetensi SDM perpustakaan, serta membangun kesadaran budaya berbagi pengetahuan.

Model usulan proses Knowledge Management di Perpustakaan Universitas Padjadjaran yaitu knowledge creation (penciptaan pengetahuan), knowledge acquisition (akuisisi pengetahuan), knowledge storage (penyimpanan pengetahuan), knowledge sharing (berbagi pengetahuan), dan knowledge aplication (aplikasi pengetahuan).

\section{DAFTAR PUSTAKA}

Aerts, G., Dooms, M., \& Haezendonck, E. (2017). Knowledge Transfers And Project-Based Learning In Large Scale Infrastructure Development Projects: An Exploratory And 
Comparative Ex-Post Analysis. International Journal of Project Management, 35(3), 224 240.

Alhazmi, F. A. (2010). Knowledge Management Issue: A Case Study Of The Department Of Educational Administration At A Saudi University, 25(1), 49-60.

Aming'a, N. N. (2015). Knowledge Capture and Acquisition Mechanisms at Kisii University. Interdisciplinary Journal of Information, Knowledge, and Management, 10, 105-116.

Anantatmula, V., \& Kanungo, S. (2010). Modeling Enablers For Successful KM Implementation. Journal of Knowledge Management, 14(1), 100-113.

Bello, A. A. (2018). Knowledge Management in Academic Libraries: Trends, Issues and Challenges. World Journal of Research and Review (WJRR), 6(2), 20-25. Retrieved from www.wjrr.org

Botha A, K. D., \& R, S. (2008). Coping with Continuous Change in the Business Environment, Knowledge Management and Knowledge Management Technology. London: Chandice Publishing Ltd.

Ceptureanu, S. I., Ceptureanu, E. G., Olaru, M., \& Popescu, D. I. (2018). An Exploratory Study on Knowledge Management Process Barriers in The Oil Industry. Energies, 11(8), 1-16. https://doi.org/10.3390/en11081977

Davenport, Thomas, H., \& Prusak., L. (1998). Working Knowledge: How Organizations Manage What They Know. Boston: Harvard Business School Press.

González, M. A., \& Bello, L. (2002). The Construct "Lifestyle" in Market Segmentation. European Journal of Marketing. 36 (1/2) Pp: 51- 85.

Gonzalez, R. V. D., \& Martins, M. F. (2017). Knowledge Management Process: aTheoretical Conceptual Research. Gestão \&amp; Produção, 24(2), 248-265. https://doi.org/10.1590/0104-530x0893-15

Hjørland, B. (2008). What is Knowledge Organization (KO)? Knowledge Organization, 35(2-3), 86-101. https://doi.org/10.5771/0943-7444-2008-2-3-86

IFLA. (2015). About The Knowledge Management Section. Retrieved from Retrieved on 18th August from \%0Awww.ifla.org

James, P. (2004). Strategic Management Meets Knowledge Management: A Literature Review And Theoretical Framework. In In Proceedings of the 5th act KM Conference. Canberra.

Lumbantobing, P. (2011). Manajemen Knowledge Sharing Berbasis Komunitas. Bandung: Knowledge Management Society.

Madge, O. . (2017). Current Stage Of Application Of The Knowledge Management Process In Romanian Academic Libraries. The 13th International Scientific Conference ELearning and Software for Education, Bucharest, Romania, April 27-28, 2017, Pp. 83-88.

Mahdi, O. R., Nassar, I. A., \& Almsafir, M. K. (2018). Knowledge Management Processes and 
Sustainable Competitive Advantage: An Empirical Examination in Private Universities. Journal of Business Research, 94, 320-334. https://doi.org/10.1016/j.jbusres.2018.02.013

Mertins, K., Heisig, P., \& Vorbeck, J. (2013). Knowledge Management: Concepts And Best Practices. Springer Science \& Business Media: Berlin, Germany, 2003; Pp. 15-24. 70.

Moleong, L. (2000). Metodologi Penelitian Kualitatif. Bandung: Remaja Rosdakarya.

Nakauchi, M., Washburn, M., \& Klein, K. (2017). Differences Between Inter-And Intra-Group Dynamics In Knowledge Transfer Processes. Management Decision, 55(4), 766-782. Retrieved from https://doi.org/10.1108/MD-08-2016-0537

Obeidat, B. Y., Hashem, L., Alansari, Tarhini, A., \& Al-Salti, Z. (2016). The Effect Of Knowledge Management Uses On Total Quality Management Practices: A Theoretical Perspective. Journal of Management and Strategy, 7(4), 18-29.

Rangkuti, F. (2015). Analisis SWOT: Teknik Membedah Kasus Bisnis. Jakarta: Gramedia.

Ranjbarfard, M., Aghdasi, M., López-Sáez, P., \& Emilio Navas López, J. T. (2014). The Barriers Of Knowled Generation,Storage,Distribution And Applicationthatimpede Learning In Sand Petroleum Companies. Journal Knowlegde Management. 2014, 18, 494-522.

Rao, S. . (2016). Use Of Knowledge Management Tools And Techniques In Academic Libraries In India: A Study',. SRELS Journal of Information Management 53(5), 1-8.

Sirorei, E. C., \& Fombad, M. C. (2019). Knowledge Management Processes at St Paul's University Library in Kenya. SA Journal of Information Management, 21(1), 1-9. https://doi.org/10.4102/sajim.v21i1.946

Tjakraatmadja, J.H., Rachman, H., \& Kristinawati, D. (2015). Personal Knowledge Management. Bandung: Institute Teknologi Bandung.

Tobing, P. L. (2007). Knowledge Management Konsep, Arsitektur, dan Implementasi. Yogyakarta: Graha Ilmu.

Yin, R. (2012). Studi Kasus: Desain dan Metode. Jakarta: Rajagrafindo Persada.

Yusup, P. M. (2012). Perspektif Manajemen Pengetahuan Informasi, Komunikasi, Pendidikan, dan Perpustakaan. Jakarta: Rajawali Pers. 
Lentera Pustaka: Jurnal Kajian Ilmu Perpustakaan, Informasi dan Kearsipan, 6 (1) 2020, 23-36 